\title{
EXERCÍCIOS COM JORNAIS
}

\section{A partir de planejamento adequado, o jornal pode ser excelente instrumento pedagógico, estabelecendo um elo entre a realidade e o currículo escolar}

Este projeto trata de uma experiência vivida em sala de aula, que apresenta uma forma diferenciada de trabalhar o jornal como riquíssima fonte de informações e excelente material para motivar a leitura, fornecendo aos alunos possibilidades de conhecer o mundo de uma forma ampla.

O projeto foi dividido em várias etapas para facilitar as formas como foi trabalhado:

$I^{\underline{a}}$ etapa: Aquisição de conhecimentos sobre o jornal. Num primeiro momento foi elaborado um caderno contendo explicações por escrito de como são divididos os assuntos do jornal.

$2^{a}$ etapa: Análise crítica e reflexão. Nesta etapa os alunos tiveram a oportunidade de ler, interpretar, refletir sobre os diversos assuntos abordados pelo jornal e analisá-los.

$3^{a}$ etapa: Exploração do jornal como fonte para o trabalho pedagógico. As matérias da terceira série - Português, Matemática, História, Geografia, Ciências, Ecologia e os Temas Transversais foram trabalhadas através de temas abordados no jornal.

$4^{a}$ etapa: Teatralização. Após a familiarização com a linguagem do jornal, os alunos tiveram a oportunidade de produzir um jornal falado nos moldes dos que são produzidos pela televisão.

Ao tomar contato com a realidade da terceira série, pude constatar que:

- os alunos desconheciam totalmente o jornal;

- havia despreparo dos alunos para ler, escrever e principalmente interpretar os textos;

- os alunos não faziam uso da linguagem apresentada pela escola, que é bem diferente da linguagem habitual da comunidade em que ele está inserido;

- as formas habituais de trabalhar o jornal não despertam interesse nos alunos;

- falar ao público (da comunidade escolar) torna-se uma tarefa difícil aos alunos.

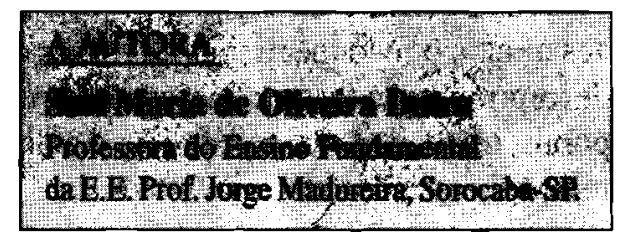




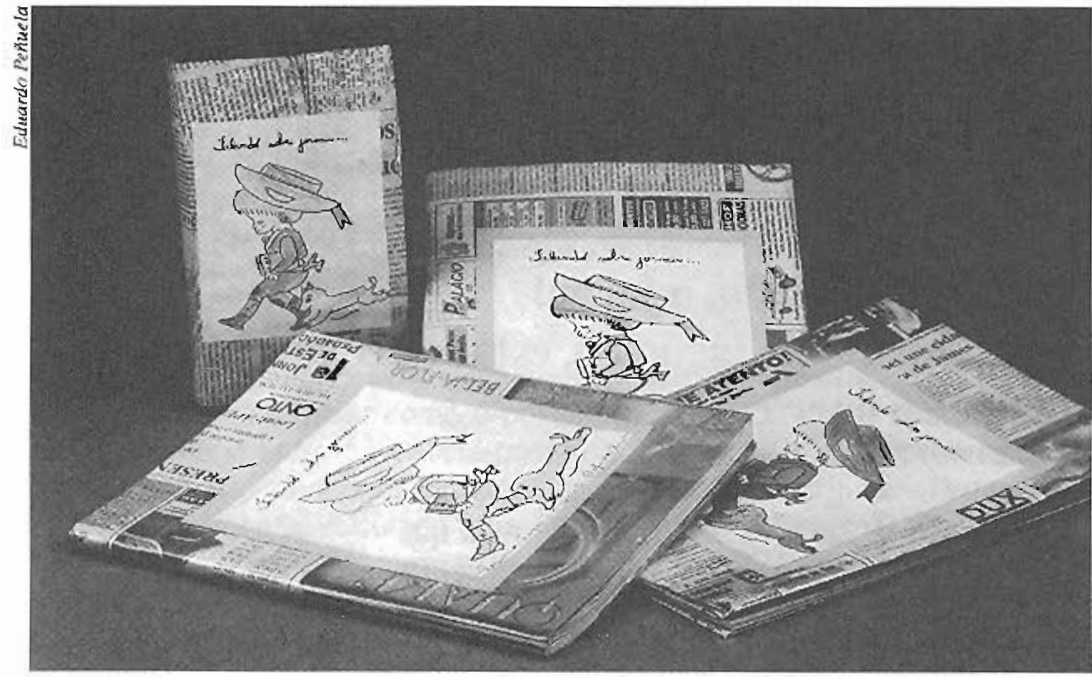

Os cadernos produzidos pelos alunos funcionam como índices de orientaçāo para entender o jornal.

\section{OB.IETIVOS DA EXPERIENCIA}

Na primeira etapa, nossos objetivos foram promover a familiarização dos alunos com o jornal e levá-los a conbecer o jomal, sua linguagem e a forma com que os assuntos são abordados por ele.

$\mathrm{Na}$ segunda etapa, ler, escrever, interpretar, refletir sobre todos os assuntos contidos no jornal e analisá-los criticamente; atualizar-se e exercer sua cidadania de forma consciente; valorizar e conhecer as características étnicas e culturais dos diferentes grupos sociais do nosso país; tomar maior contato com as desigualdades socioeconômicas da nossa sociedade; analisar criticamente as relações sociais discriminatórias excludentes que permeiam a sociedade brasileira; oferecer possibilidades aos alunos de conhecer o Brasil como um país complexo, multifacetado e muitas vezes paradoxal; introduzir os temas transversais de forma consistente e presente durante as aulas.

Em uma terceira etapa, estabelecemos como principais objetivos trabalhar todas as matérias da terceira série através de assuntos que despertassem interesse nos alunos; demonstrar aos alunos a necessidade real de aprender as matérias abordadas pela escola e sua utilidade; perceber que existem diferentes pontos de vista ao conhecer um assunto.

Na quarta e última etapa, nossos abjetivos foram: proporcionar aos alunos o reconhecimento e a integração com os colegas nas cenas de improvisação teatral; compreender os significados expressivos, corporais, textuais e sonoros da criação do jornal falado; experimentar as relações entre homem e realidade com interesse e curiosidade, exercitando a discussão e a indagação, argumentando e apreciando a produção da classe. 
Ao desenvolver a primeira etapa dessa experiência, acredito que inovei no que diz respeito ao trabalho com jornal. Foi a fase mais importante do projeto, pois através dela pude proporcionar aos alunos conhecimentos sobre o jornal, possibilitando o desenvolvimento do interesse e da compreensão dos assuntos abordados.

Nos cursos que fiz para desenvolver o projeto Jornal na Escola, foram sugeridos aos professores atividades de leitura, compreensão, produção, reprodução de textos, propagandas e anúncios. Mas ao tentar traballhar da forma proposta, fui aos poucos percebendo que as atividades não despertavam interesse nos alunos. Analisando as causas dessa dificuldade, pude concluir que os alunos desconheciam o jornal e portanto não conseguiaun perceber a utilização desse material em suas vidas.

Os assuntos abordados pelo jomal já haviam sido explicados aos alunos através de conversas informais, porém, por toda a diversidade contida nele, as crianças não conseguiam reter o que thes era explicado.

Foi então que tive a idéia de fazer com que os alunos escrevessem em um caderno o que cada assunto significava. Depois $\mathrm{fiz}_{\mathrm{z}} \mathrm{com}$ que eles pesquisassem no jornal onde estava aquele assunto, e recortassem e colassem junto à sua explicação.

Esta etapa se prolongou por vários dias, até que o jornal pôde ser compreendido pela classe.

Após a conclusão deste trabalho, cada aluno possuía um caderno contendo todas as explicações necessárias dos assuntos abordados pelo jornal que, por diversas vezes, haviam tido a oportunidade de manusear e pesquisar. Esse cademo agora é utilizado como se fosse umn dicionário sobre jornal.

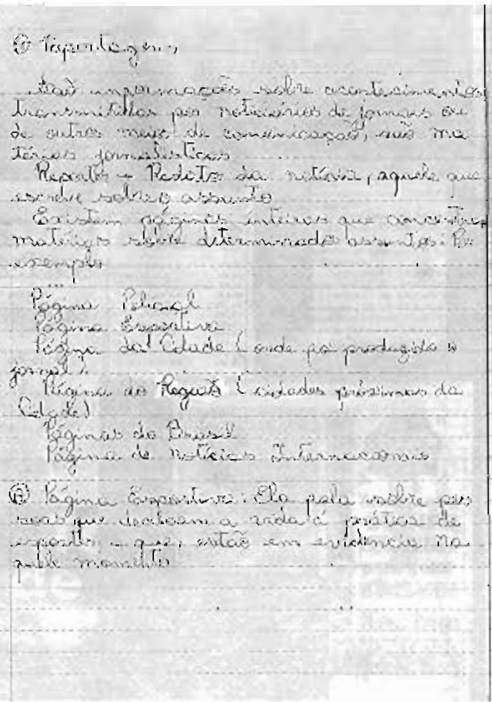

Equipe de Suzano apresenta neforços

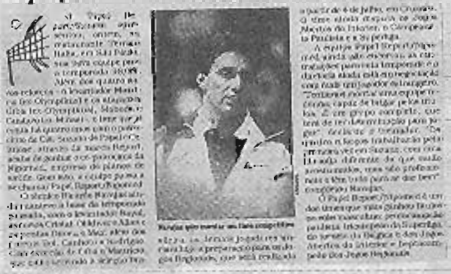

(a) ?

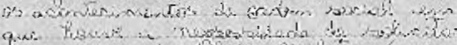

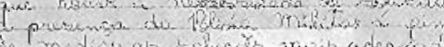

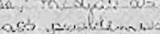

Jovem é sequestrada durante roubo

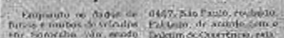

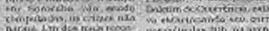

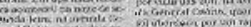

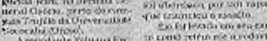

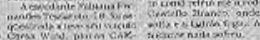

A aluna Roseinéia Lopes, da terceira série I, define o verbete reporiagem e anexa um exemplo coletado do jornal. 
Como os alunos já estavam familiarizados com o jornal e conseguiam identificar com facilidade os assuntos contidos nele, pudemos iniciar uma nova etapa - a segunda -, que tinha a proposta de ler e compreender os assuntos do momento, rfletir sobre eles e analisá-los.

\section{REALIDADE COTIDIANA AMPLIADA}

Inicialmente, selecionei assuntos da nossa cidade e, aos poucos, outros de abrangência estadual, nacional e mundial foram sendo introduzidos. A partir daí, o trabalho com o jornal tornou-se interessante aos alunos, pois começaram a pensar sobre os acontecimentos e procurar analisá-los, percebendo que eles estavam diretamente ligados às suas vidas ou das pessoas que os cercam.

As matérias abordadas na escola - Português, Matemática, História, Geografia, Ciências, com tratamento que atendesse aos temas transversais - começaram a fazer sentido e eles perceberam a necessidade de conhecê-las melhor para compreender os vários pontos de vista de um assunto.

Matérias do currículo da terceira série foram selecionadas e introduzidas a partir de assuntos retirados do jornal, dando início ao desenvolvimento da terceira etapa de nosso projeto de trabalho.

Para as aulas de Português solicitei aos alunos a produção de textos para anunciar imóveis, automóveis e ofertas de empregos. Eles foram orientados para elaborar propagandas de objetos (recortados), aproveitando os encartes publicitários contidos no jornal. Para facilitar essas produções, elaborei um roteiro que dava sugestões de como deveria ser feito:

Roteiro para anúncio de Empregos:
A. Título;
B. O que o candidato deve saber;
C. Quanto tempo de experiência é necessário;
D. O que a empresa oferece e qual é o salário;
E. Quais os documentos que o candidato deve levar;
F. Onde (endereço) o candidato deve comparecer, se quiser nome da pessoa que o candidato deve procurar.

Roteiro para anúncio de Veículos:
A. Título;
B. Modelo, ano e cor; 
C. Condições do veículo (lataria, motor, pneus, bancos etc.);

D. Condições de pagamento (à vista, a prazo, se aceita troca etc.);

E. Onde dirigir-se para examinar o carro.

Roteiro para anúncio de Imóveis:

A. Título destacando o tipo de imóvel;

B. Onde está localizado;

C. O que tem o imóvel (cômodos com detalhes);

D. Condições de pagamento (à vista, a prazo, se aceita troca);

E. Onde dirigir-se para avaliar o imóvel, nome do vendedor.

Além dessas atividades, aproveitei também, para as aulas de Português, as bistórias em quadrinhos, sem legenda, para a reprodução de textos. Esta atividade mostrou-se excelente quanto à motivação durante a produção.

Para trabalhar Matemática, pedi aos alunos que recortassem dos encautes publicitários diversos objetos que, depois de colados, puderam ser utilizados em situações-problema. Através deles pudemos criar situaçōes de compra e venda, formas de pagamento (à vista, a prazo), em dinheiro e em cheques (preenchimento),

Para os conteúdos de História, partímos da eviclência de que os assuntos dá História contemporânea estão diretamente ligados aos assuntos do passado. Dessa forma, durante a leitura dos jornais tive diversas oportunidades de informá-los sobre a nossa História passada, demonstrando como esses acontecimentos interferíram na nossa vida atualmente. Acredito que esses assuntos foram abordados oportunamente, aproveitando o interesse dos alunos naquele momento. Dentro dos assuntos em evídência deste primeiro semestre, a Copa do Mundo foi um dos que mais interesse despertou.

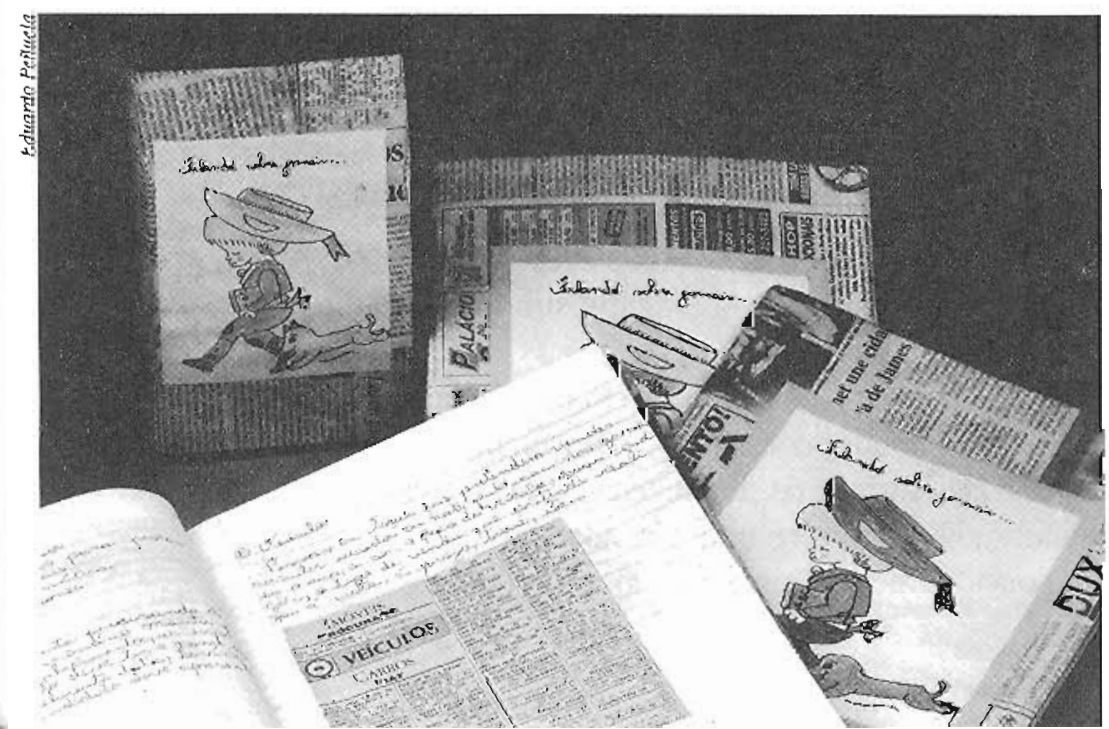

Daniel Cordeiro Viana define 0 que é o caderno de classificados de veículos. 
Trabalhei Geografia de forma bem diversificada, tornando-a bastante interessante. Toda vez que os jornais abordavam assuntos de outras localidades, elas foram aproveitadas para que os alunos conhecessem e utilizassem mapas, globo terrestre e outros recursos de que a escola dispõe. Assim, eles puderam localizar-se de forma mais concreta, conhecendo os locais mencionados pelas reportagens.

Foram muitas as oportunidades em que pudemos conversar sobre saúde, prevenção de doenças, nutrição e higiene. Dentro desses temas, a dengue foi um dos assuntos mais falados, por estar em evidência nos jornais naquele momento. Ficou mais claro para eles como os temas tratados nas aulas de Ciências e Saúde estão relacionados com a vida das pessoas.

Durante o planejamento, os professores foram incentivados a trabalhar os temas transversais - ética, diálogo, respeito mútuo e solidariedade - de forma constante na sala de aula. Através da leitura dos jornais pude introduzir esses temas, sempre presentes em nossas conversas.

\section{JORNAL FALADO E AVALIAÇÃO}

Às vésperas do final do primeiro semestre, meus alunos e eu elaboramos um jornal falado para que pudéssemos abordar alguns dos assuntos estudados. Uma filmadora - novo recurso que a escola disponibilizou - foi utilizada para registrar a produção da classe. A filmagem do jornal falado não se preocupou com o acabamento final, nem com os possíveis erros nele contidos. A intenção principal foi oferecer uma oportunidade aos alunos de se utilizarem de outro tipo de linguagem para a criação e a expressão de seus anseios.

Através do jornal falado, os alunos puderam experimentar as relações entre os fatos imaginários e a realidade do seu cotidiano.

Analisando meus alunos, pude constatar que este projeto produziu bons frutos em todas as áreas. É muito difícil mensurar o que foi aprendido, porém percebi que houve mudanças na forma de pensar, agir e de se comunicar. Ficou evidente que os alunos adquiriram uma bagagem de conhecimentos superior à da expectativa inicial, o que me deixa muito feliz, certa de que valeu a pena desenvolver o projeto.

Um dos sintomas de maior relevância no momento de avaliar um projeto é a freqüência e o comportamento dos alunos. Nesse sentido não tive problemas no primeiro semestre, o que demonstra que as aulas estavam bastante atrativas aos alunos.

Os conteúdos e objetivos propostos no planejamento foram além do esperado, pois através dos jornais os alunos puderam ler, escrever, produzir e reproduzir textos com diversas formas de linguagem. Através dos encartes publicitários, os alunos também conseguiram entender e solucionar problemas matemáticos, pois tratava-se de situações do seu cotidiano. 
Sempre que se trabalha História através de livros didáticos, ela se torna fria e distante dos alunos. Através dos jornais, esses temas foram trabalhados dentro dos interesses dos alunos, que assimilaram com facilidade os assuntos abordados. Os temas de Geografia também puderam ser trabalhados de forma mais coerente e consistente. Os alunos conheceram os efeitos para depois se interessarem pelas causas daqueles problemas: assim a Geografia foi trabalhada de forma muito interessante. Os temas sobre saúde, prevenção de doenças, nutrição e higiene foram abordados dentro da realidade dos alunos, sendo assimilados mais facilmente. Os temas transversais foram trabalhados constantemente e, pela discussão e reflexão, buscamos desenvolver nos alunos a conscientização dos problemas da sociedade moderna, promovendo mudanças comportamentais necessárias para uma sociedade mais justa.

O exercício de produção de um jornal falado proporcionou aos alunos momentos de integração com o grupo, analisando-se crítica e construtivamente, exercitando a discussão e a argumentação para elevar a qualidade do trabalho.

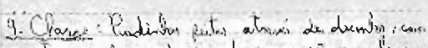

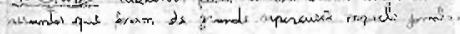

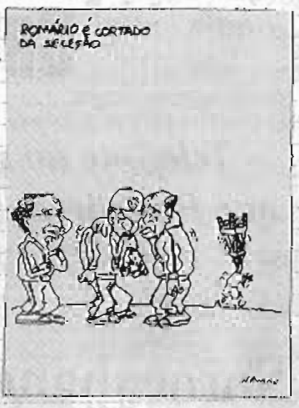

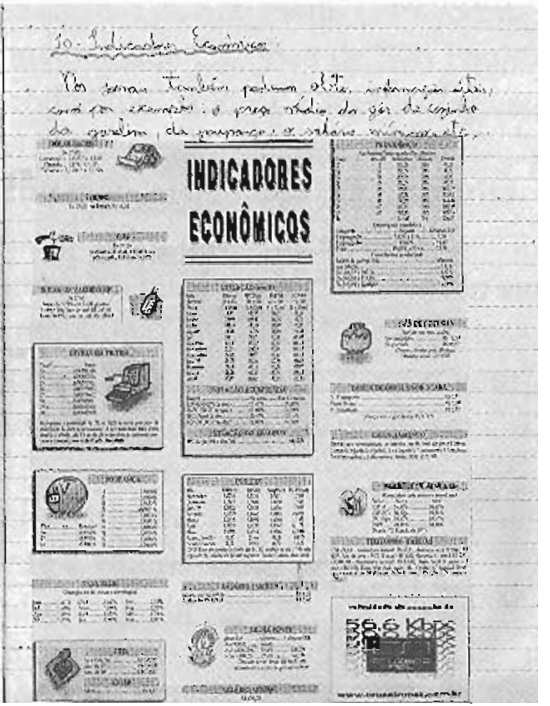

Juliana Calça, da terceira série I, define a charge $e$ explica o que são indicadores econômicos. 
Resumo: Professora da terceira série do Ensino Fundamental de escola pública da cidade de Sorocaba, São Paulo, relata planejamento e execução de experiència pedagógica desenvolvida com o jornal em sala de aula. O trabalho foi planejado em quatro etapas, partindo da realidade dos alunos que, num primeiro momento, necessitaram compreender como o jornal pode ser manuseado, servir para pesquisa e ajudar a compreender os temas locais, nacionais e internacionais. Posteriormente, desenvolveu o trabalho usando o jornal como fonte de informação, introduzindo os temas das disciplinas do currículo. Ao final, elaborou, junto com os alunos, um jornal falado.

Palavras-chave: jornal, sala de aula, projeto pedagógico, escola pública
Abstract: A third-grade teacher in a public school in the city of Sorocaba, São Paulo, reports on the planning and execution of a teaching experience using the newspaper in the classroom. The work was planned in four stages, starting at the level of the students' reality who, at first, need to understand how the newspaper can be handled, how it can be used for research, and how it helps one to understand local, national and international themes. The project was then continued by using the newspaper as a source of information for the disciplines in the school curriculum. Finally, together the students, a "spoken" paper was put together.

Key words: newspaper, classroom, teaching project, public school 